\title{
Fer química amb dues lectures sobre la xocolata
}

\author{
Núria Solsona i Pairó \\ Servei de Formació del Personal Docent. Departament d'Educació \\ nsolsona@xtec.cat
}

L'article analitza l'ús de dues lectures sobre la xocolata en una classe de química de $4 t$. d'ESO, durant les quals es desenvolupen algunes competències comunicatives $i$ socials, d'altres relacionades amb el coneixement i interacció amb el mon i la més fonamental d'autonomia i iniciativa personal.

Paraules clau: lectura de textos, competències bàsiques, química, contextualització

\section{Introducció}

L'article recull algunes activitats d'aula que s'inclouen en una seqüència didàctica d'iniciació a la química a 4t. d'ESO, en context culinari. El treball s'ha fet amb dues lectures, una d'informativa sobre "Les propietats culinàries de les substàncies" i una altra sobre l'estructura interna de les substàncies.

En el primer apartat de l'article es repassa el marc teòric didàctic en el qual s'inscriu la reflexió, incloent-hi la mirada competencial, entesa de forma àmplia.

En el segon apartat es descriuen les dues lectures fetes a classe, indicant la seva inserció en la seqüència didàctica, s'expliquen les activitats que es van desenvolupar i l'evolució de les idees científiques de l'alumnat a l'entorn de la xocolata.

En el tercer apartat es recullen i analitzen algunes respostes i explicacions de l'alumnat després de fer la segona lectura.

\section{Marc teòric}

El treball competencial a l'àrea de ciències experimentals requereix seqüències didàctiques contextualitzades, és a dir que parteixin de l'anàlisi d'una situació real amb l'objectiu que l'alumnat aprengui a explicar teòricament els fenòmens del seu entorn. Per això cal posar les bases que desenvolupin el pensament teòric sobre els fenòmens del món a partir de les experiències i explicacions de noies i nois, fent atenció al llenguatge en l'aprenentatge de les ciències. I valorar igualment el coneixement formal i explícit dels sabers i les creences intuïtives, informals; assumir que els sabers verbals, abstractes o formals no són superiors als sabers pràctics concrets i informals, i tenir en compte que la nostra pròpia arquitectura emocional-mental, basteix les nostres identitats travessades pel biaix del gènere per introduir una nova mirada que permeti desenvolupar un treball competencial satisfactori.

Totes les activitats d'aprenentatge són multicompetencials, però a partir de les activitats organitzades entorn de la xocolata, les dues lectures de textos i la preparació de la xocolata desfeta o d'un batut de xocolata, podem assenyalar algunes de les competències que de manera global es poden prioritzar i desenvolupar, tenint en compte que per definició una competència és quelcom holístic. L'enculturització produeix experiències i vivències distintes en dones i homes i en general les identitats de gènere que construïm responen als estereotips d'una masculinitat i d'una feminitat hegemòniques jerarquitzades. Per això cal tenir en compte la influència de la diferència sexual en el treball competencial que proposem a les noies i als nois durant el procés d'aprenentatge.

La lectura «L'estructura de les substàncies i el seu sabor», a nivell de competències comunicatives permet desenvolupar la comprensió del significat d'un text escrit considerant el seu context, i de 
ser capaç d'aplicar habilitats lectores per millorar la comprensió d'un document científic. És a dir, reconèixer la idea principal del text, el significat de paraules desconegudes i la progressió del text (Marquez i Prat, 2010). La competència d'aprendre a aprendre, referida al treball eficient d'expressar i comunicar les pròpies idees, es desenvolupa en la mateixa lectura. El gust per aprendre i l'adquisició de la consciència de les pròpies capacitats, estratègies i recursos intel-lectuals, emocionals i físics es treballa en la realització de l'experiment de preparació de la xocolata desfeta o d'un batut de xocolata i el treball cooperatiu del grup.

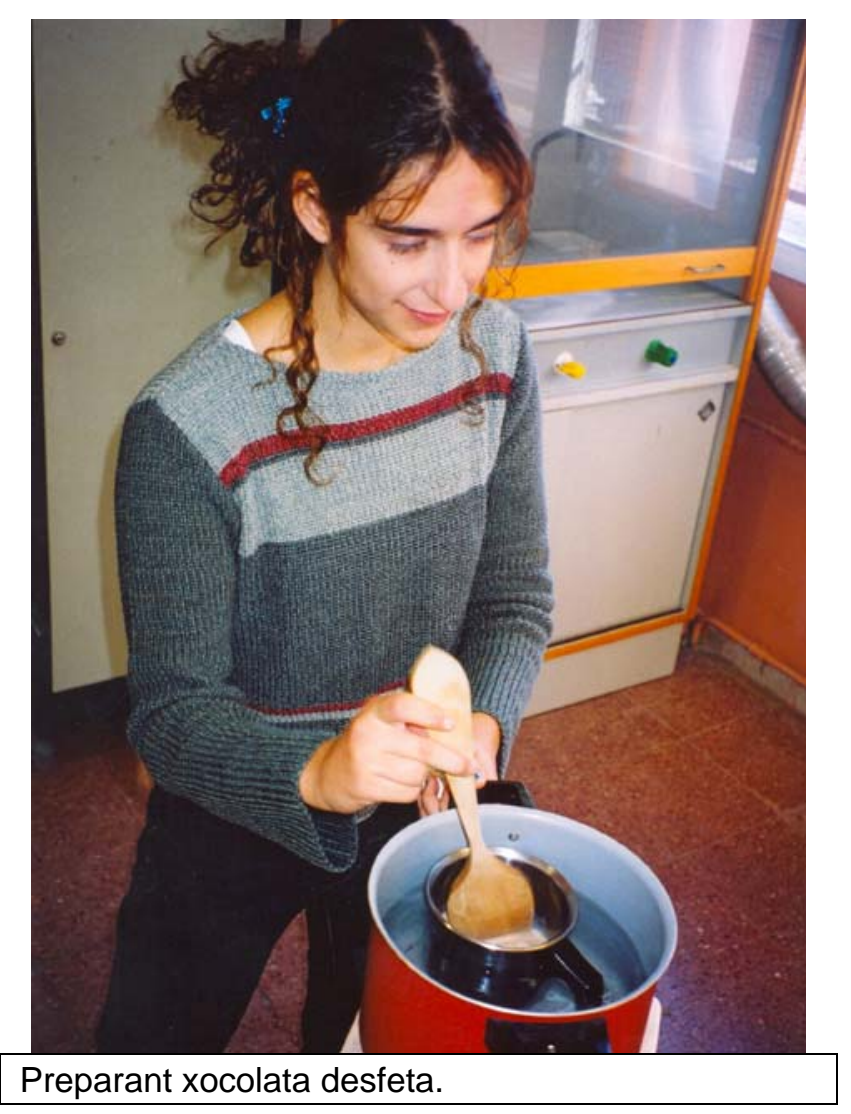

Pel que fa a la competència social i ciutadana, les activitats ajuden a desenvolupar la superació de la visió androcèntrica del món, en la mesura que es treballa una substància, la xocolata, que tradicionalment no ha estat objecte d'estudi de la química, tot i que probablement l'alquímia més primitiva sí que li va dedicar atenció.

Finalment, en l'àmbit de la competència de coneixement i interacció amb el mon, les activitats a l'entorn a la xocolata i qualsevol activitat o seqüència didàctica en context culinari introdueixen una valoració no jerarquitzada dels sabers, en utilitzar els sabers culinaris com a context d'aprenentatge dels coneixements químics. I permeten desenvolupar la inclusió de referents femenins en els diferents àmbits dels sabers, i la incorporació en el currículum dels sabers i les experiències de les dones.

L'experiment de preparació de la xocolata desfeta, com a qualsevol altre experiment culinari que es plantegi com a petita investigació -on per exemple es proposa la preparació d'un col-loide buscant el procediment a seguir-suposa el desenvolupament de la competència d'autonomia i iniciativa personal en el treball col-lectiu, pel que fa a l'escolta atenta i la presa de decisions (Solsona, 2010).

\section{La lectura de textos sobre la xocolata}

En una classe de química no sempre trobem materials i substàncies adequats al treball competencial a l'aula i al laboratori com la xocolata, una substància d'atenció preferent per l'alumnat. La xocolata no és un material fàcil de classificar des del punt de vista físico-químic, és un col-loide però no és fàcil escatir quin tipus de col-loide. Veiem que la bibliografia parla molt del seu origen, la seva composició i de l'elaboració de la xocolata.

Les activitats d'aula s'han fet en context culinari (Solsona, 2003) i pretenen ajudar a desenvolupar el pensament teòric sobre els fenòmens del mon a partir de les explicacions quotidianes, introduir els models científics més bàsics i utilitzar-los per a millorar la comprensió de fenòmens senzills, així com promoure la reflexió sobre les interaccions entre ciència, tecnologia i societat (Aliberas i Solsona, 2009). Un dels primers experiments culinaris de la seqüència és la preparació de «Mescles i dissolucions per esmorzar», i algun grup de la classe espontàniament prepara xocolata desfeta com a exemple de mescla, tot i que després aprendran que és un col-loide. Finalment, l'experiment paradigmàtic per a l'aprenentatge del canvi químic és el pa de pessic i moltes vegades entre els seus ingredients hi ha la xocolata (Solsona, 2005).

Llegir no és conèixer les paraules, no és un procés lineal ni una acumulació de significats, i tampoc no es redueix a la simple localització de la informació (Solsona, 2010). La primera lectura «Les propietats culinàries de les substàncies» facilita informació sobre la xocolata, la seva composició, propietats i utilitats. I a partir de la lectura l'alumnat construeix una primera fitxa sobre la xocolata amb aquesta informació.

Posteriorment, seguim el procés de conceptualització de la xocolata i altres materials, i per intro- 
duir l'estructura interna de les substàncies proposem fer la lectura: «L'estructura de les substàncies i el seu sabor», que és una adaptació de l'article de la revista Newton, del febrer 2001. El text serveix d'exploració a l'inici de la seqüència didàctica sobre el model atomicomolecular.

La segona lectura «L'estructura de les substàncies i el seu sabor» s'ha de dur a terme després d'haver treballat les substàncies i les seves propietats. Perquè l'activitat sigui d'exploració, és cabdal abans de començar-la fer fixar a l'alumnat que el text parla de la xocolata, per tal conèixer el seu punt de partida, d'activar tota la informació que pugui tenir sobre el tema i potenciar una primera representació del contingut de la lectura. Per això pot ser útil preguntar a la classe: A qui no li agrada la xocolata? Quina us agrada més la xocolata negra, amb llet o la blanca? Sabeu les característiques de la xocolata més bona?

El text adaptat diu: "Algunes rajoles de xocolata són més bones que d'altres, encara que continguin els mateixos ingredients i hagin estat elaborades amb el mateix procediment. Durant la solidificació de la xocolata, les seves molècules es poden agrupar de sis maneres diferents. En el laboratori de la fàbrica Nestlé, van observar que una mescla de cacau i de mantega de cacau (ingredient principal que dóna gust a la xocolata) dissolta a 50 ${ }^{\circ} \mathrm{C}$, solidificava si li reduïen dràsticament la temperatura a $22{ }^{\circ} \mathrm{C}$. Es formen cristalls diferents segons la temperatura de solidificació que es poden determinar mitjançant raigs $\mathrm{X}$. El cristall òptim, el que resulta més saborós es forma a 23,86 'C".

Els objectius d'aprenentatge sobre la lectura són establir relacions entre l'estructura interna de les substàncies a nivell microscòpic i la solidificació, i comprendre la influència de la temperatura de solidificació de la xocolata.

Els objectius de lectura són els de crear contextos de lectura que apropin l'alumnat a la comprensió del seu entorn social, en concret de les substàncies alimentàries i verbalitzar les opinions de l'alumnat sobre estratègies comercials relacionades amb fenòmens científics. I aprendre a llegir articles periodístics des de la perspectiva de la química, és a dir del model atomicomolecular.

Es proposa a l'alumnat que llegeixi el text fent atenció als conceptes científics. La lectura collectiva, amb les preguntes d'acompanyament comporta que l'alumnat escrigui les que considera idees principals i la seva opinió sobre la informació que subministra el text entorn a la fabricació de la xocolata. En algunes classes es proposa llegir el text en veu alta ja que és curt i segons la tipologia d'alumnat així es capta millor l'atenció. Però en la majoria de classes, el text resulta prou interessant $\mathrm{i}$ sorprenent com per fer la lectura i la resposta a les preguntes de manera individual. Un cop llegit el text i escrites les respostes, fem la posada en comú i llegim en veu alta les que s'hagi observat o detectat que són més significatives.

\section{Anàlisi de les respostes de l'alumnat després de la lectura de “L'estructura de les substàncies i el seu sabor»}

S'han recollit les respostes de 20 noies i 14 nois. Per a un grup, la idea principal és "El gust de la xocolata segons la seva fabricació" i, "Fer un producte (xocolata) que sigui de més bona qualitat $i$ així vendre més". Un segon grup dóna respostes que són el producte d'una lectura literal i fan referència a la temperatura de fabricació o solidificació de la xocolata. Per exemple diuen: "depèn de la temperatura que dissolgui la xocolata pot arribar a solidificar-se a 22 graus", "la mescla de cacau amb la mantega de cacau dissolta a diferents graus centígrads per donar-li diferents sabors a la xocolata i així vendre més", "la millor temperatura de solidificació és de 23,86 graus ja que els cristalls que es formen són els més saborosos", i "la fàbrica Nestlé ha esbrinat el punt exacte de solidificació de la xocolata perquè el seu sabor sigui el més bo per al nostre paladar".

Després de la segona lectura, només un últim grup fa referència a l'estructura interna de la xocolata, tot dient: "depèn de la temperatura a la que es realitzi la solidificació de la xocolata, les seves molècules s'agrupen de forma diferent $i$ el gust varia molt", $i$ "les molècules es poden agrupar de sis maneres diferents, ja que les forces d'atracció són diferents".

Preguntar l'opinió sobre el text de la xocolata és una via per activar les experiències de l'alumnat i la seva sorpresa: "M'ha sorprès i no ho sabia que depengués de la temperatura de solidificació que una xocolata sigui més gustosa que una altra. Crec que és interessant saber-ho", "M'ha sorprès una mica saber que d'aquesta manera es pot controlar el sabor d'un producte al fer-lo, pensava que només es feia amb additius", "És interessant que sigui per aquest raó (temperatura de solidificació) i no pels ingredients", "Jo no ho sabia i mai ho havia sentit a dir. Tampoc m'imaginava que dues xocolates iguals, fetes amb els mateixos ingredients $i$ proporcions, una pogués ser més saborosa que l'altra. He après una cosa nova", "Mai m'havia fixat quan tastava la xocolata pels ingredients que està feta, encara que tingués diferents gustos".

Un altre grup de respostes recull la perspectiva comercial de la informació científica com a perso- 
nes consumidores i diuen: "Està bé que es preocupin de buscar diferents temperatures per solidificar la xocolata, si és més gustosa i evidentment vendre més", "No ho sabia i em sembla molt bé que es preocupin per millorar el producte pels consumidors, més si són d'alimentació", "Està bé que donin molta més informació, dir exactament a la temperatura en que es troba", "No ho sabia, em pensava que tota la xocolata es feia igual", "La fàbrica Nestlé ha estat molt llesta en esbrinar el procediment de fabricació en que quedi més bona", i "No m'ha sorprès gens perquè la xocolata Nestlé és molt bona, té una bona empresa i molts efectius treballant". Un noi diu: "Mai no havia pensat que coses tant quotidianes com la xocolata amaguin un procés químic i tecnològic tant rellevant", però hi ha 3 nois que no escriuen la seva opinió sobre el text.

Una noia mostra la seva satisfacció, tot i que fa un ús macroscòpic dels conceptes microscòpics, quan diu: "La xocolata és una bona manera d'aprendre química perquè a tots en agrada i els cristalls que sorgeixen quan trenquem la xocolata ens permeten veure 'els àtoms'" i una altra diu: "Jo penso que està bé que hagin esbrinat tot això, perquè de vegades quan menges una xocolatina té un sabor amargant perquè té molt de cacau". Finalment, una noia expressa el seu desig dient: "Haurien de fer de manera que totes les molècules s'agrupessin d'igual manera perquè totes les rajoles de xocolata fossin bones".

\section{Valoració de les respostes a la lectura}

El text «L'estructura de les substàncies i el seu sabor» presenta característiques divergents respecte dels llibres de text i possibilita l'aprofundiment de la relació de la ciència amb la vida de l'alumnat. El text parla de la xocolata, un material molt proper i apreciat per l'alumnat de la ESO i el fer referència al sabor de la xocolata potencia les estructures afectives i fa que no hi hagi divorci entre el text i la persona lectora. Les opinions de l'alumnat sobre el text mostren que la seva lectura sorprèn i resulta atractiva i suggerent.

Un grup de respostes de l'alumnat només parlen de les característiques de la xocolata, sense fer referència a la idea principal del text, la relació que hi ha entre la temperatura de solidificació de la xocolata i la seva estructura interna. En alguns grups el context culinari ajuda a fer el pas de parlar de "característiques" de la xocolata a conceptualitzar les "propietats" de la xocolata. S'observa que el gust de la xocolata és una informació molt rellevant per a l'alumnat.
El text funciona com a mediador de la interacció escolar i provoca la reflexió d'una majoria de l'alumnat sobre la relació entre la solidificació i l'agrupació de les molècules. Perquè l'alumnat pugui captar la idea principal del text és requereix l'ús de l'atenció i de la memòria operativa. Les opinions de l'alumnat sobre el text són molt variades i mostren sorpresa davant de la informació del text per la relació que s'estableix entre la fabricació de la xocolata, la temperatura i el seu sabor. Quan fan referència a la temperatura de fabricació o solidificació de la xocolata relacionant-la amb el gust, no aprecien la jerarquia que hi ha entre la informació alimentària i la científica que conté el text.

A 4t. d'ESO, en general les primeres idees $i$ conceptes sobre l'estructura de les substàncies són bastant difosos. Per exemple, s'observa l'ús del concepte estructura com si fos exclusivament macroscòpic, és a dir a nivell semblant a l'estructura dels minerals però sense relacionar-ho amb l'estructura atòmica molecular. D'altra banda, de vegades s'observa que l'alumnat estableix una relació molt feble entre l'existència d'àtoms i molècules que ja coneix amb l'estructura de les substàncies. En algunes respostes semblaria com si fossin conceptes independents. Per això, cal centrar l'atenció de l'alumnat en els conceptes indispensables per comprendre la relació entre la temperatura de solidificació i el gust de la xocolata, per tal d'ajudar a avançar en el procés de modelització de l'estructura interna de les substàncies. Les 20 noies i 14 nois de les dues aules que van fer la lectura han expressat idees principals diferents, tot i que només dues noies relacionen la solidificació amb l'agrupació de les molècules. D'entrada, l'explicació microscòpica de la solidificació no sembla rellevant ni significativa per a la majoria de l'alumnat, ja que el text es presenta en l'exploració de la seqüència didàctica sobre la teoria atòmic molecular. Un grup de respostes recullen només una part de la idea principal, el gust o el procés de fabricació de la xocolata, sense fer esment de la temperatura ni de la solidificació de la xocolata i un altre grup donen explicacions macroscòpiques.

En resum, aquest article vol recollir el més essencial d'un experiència que vol fer química a través del llenguatge i de la cuina.

\section{Bibliografia}

ALIBERAS, Joan; SOLSONA, Núria; (2009) Factores que determinan la supervivencia de una innovación educativa. Enseñanza de las Ciencias, 27(3), $393-404$. 
MÁRQUEZ, C.; PRAT, A. (2010). Competència científica i lectora a secundària. L'ús de textos a les aules de ciències. Barcelona: Rosa Sensat. Quaderns de Rosa Sensat,

SANMARTÍ, Neus (2010). Aprender a leer críticamente las ideas y pruebas que aporta artículos periodísticos. Indagación y competencias científicas. Ávila.
SOLSONA i PAIRÓ, Núria (2003). El saber científico de las mujeres. Madrid, TALASA.

SOLSONA i PAIRÓ, Núria (2005). Una introducció a la química des de la cuina. Ciències, 1, 12-15. http://crecim.uab.cat/revista_ciencies/revista/nu meros/numero\%20001/index.htm

SOLSONA i PAIRÓ, Núria (2010). Una experiencia competencial de química y bizcochos en el aula. Aula, 188, 52 -55. 